\title{
Pertanian Konservasi di Areal Pegunungan Cycloop Kabupaten Jayapura Papua
}

Yaved Muyan a dan Ivonne F. Mariay ${ }^{b}$

${ }^{a}$ Fakultas Pertanian, Universitas Papua, Manokwari, Papua Barat, Indonesia.

${ }^{b}$ Fakultas Pertanian, Universitas Papua, Manokwari, Papua Barat, Indonesia.

\section{Article Info}

Article history:

Received 8 Agustus 2016

Received in revised form 20 Desember 2016

Accepted 9 Februari 2017

\section{Keywords:}

Sistem Pertanian

Konservasi

Cycloop

\section{Abstrak}

Penelitian ini bertujuan untuk mengetahui penerapan sistem pertanian konservasi di Kawasan Cagar Alam Pegunungan Cycloop. Metode yang digunakan dalam penelitian ini adalah metode deskriptif dengan teknik observasi dan wawancara. Variabel penelitian yang diamati meliputi kegiatan tindak agronomi, kepemilikan luas lahan, jenis-jenis komoditi, pola unsur-unsur iklim, tindak agronomi berbasis konservasi. Kegiatan tindak agronomi terdiri dari pengolahan tanah, pola tanam, jarak tanam, pemupukan, pemeliharaan dan pengendalian hama penyakit tanaman, Rata-rata kepemilikan luas lahan adalah $2131 \mathrm{~m}^{2}$. Berdasarkan data yang diperoleh dari responden dilapangan terdapat 19 jenis komoditi yaitu 4 jenis komoditi tanaman pangan dan 15 tanaman hortikultura. Penggunaan unsur-unsur iklim dalam penelitian ini adalah untuk mengamati pola dari masing-masing unsur iklim terutama curah hujan yang akan dihubungkan dengan tindak agronomi dan tindak konservasi yang dilakukan pada areal pegunungan Cycloop. Berdasarkan pola curah hujan dapat disesuaikan dengan jenis komoditi yang akan ditanam yaitu pada bulan November sampai Maret adaah komoditi jagung dan pisang, dan pada periode bulan April sampai Oktober dapat ditanam komoditi legume, ubi-ubian dan sayuran. Sehingga areal disekitar pegunungan Cycloop selalu tertutup serta banjir dan erosi dapat diminimalisir. Umumnya penggunaan tindak agronomi di areal pegunungan Cycloop perlu diterapkan dengan optimal, sehingga perlu pendampingan bagi para petani di areal pegunungan Cycloop. (02017 dipublikasikan oleh Savana Cendana.

\section{Pendahuluan}

Papua merupakan salah satu wilayah Indonesia yang diketahui memiliki sumber daya alam yang sangat kaya, namun kurangnya pengetahuan terhadap hak masyarakat terjadi karena kurang diakuinya peran masyarakat di dalam pengelolaan sumber daya alam, oleh sebab itu masyarakat hanya menggunakan pengetahuan lokal untuk memanfaatkan sumber daya alam sebagai bagian dar mata pencaharian untuk kelangsungan hidup. Keadaan ini membuat masyarakat tidak memiliki hak penuh dalam pengambilan keputusan yang dapat member pengaruh besar bagi peningkatan kesejahteraan dan perbaikan kehidupan masyarakat. Sejalan dengan meningkatnya pertumbuhan penduduk, meningka pula kebutuhan akan bahan pangan. Peningkatan jumlah penduduk di Kabupaten Jayapura tentunya menyebabkan perubahan fungsi lahan yang mengarah pada areal konservasi pegunungan Cycloop. Hal-hal ini menyebabkan terjadi degradasi fungsi areal konservasi pegunungan Cycloop.

Ap et al., (2010) menyatakan bahwa sebagian besar masyarakat yang bermukim di kawasan cagar alam pegunungan Cycloop bermata pencaharian pokok sebagai petani. Hal ini karena kegiatan pertanian sudah merupakan tradisi turun temurun dari nenek moyang. Kabupaten Jayapura termasuk pegunungan Cycloop dengan curah hujan rata-rata $3276 \mathrm{~mm}$ per tahun menggambarkan kondisi iklim basah, dengan curah hujan yang cukup tingg mengakibatkan pada saat musim hujan, banyak air hujan yang jatuh kepermukaan bumi. Dan apabila pada areal tersebut telah terjadi perubahan alih guna lahan akibat dari perladangan berpindah maka, dibagian hulu sungai resapan air ke dalam tanah menjadi lebih kecil.

Widianto et al,. (2003) menyatakan bahwa alih-guna lahan hutan menjadi lahan pertanian disadari menimbulkan banyak masalah seperti penurunan kesuburan tanah, erosi, kepunahan flora dan fauna, banjir, kekeringan dan bahkan perubahan lingkungan global. Tujuan dari penelitian ini yaitu untuk mengetahui dan menerapkan sistem pertanian konservasi di Kawasan Cagar Alam Pegunungan Cycloop. Dari hasil penelitian ini diharapkan dapat menjadi bahan informasi bagi instansi terkait dan terutama bagi masyarakat yang bermukim serta melakukan aktivitas pertanian disekitar kawasan pegunungan Cycloop.

\section{Metode}

Penelitian ini dilaksanakan pada kebun petani di areal pegunungan Cycloop yang meliputi tiga tempat yaitu Kelurahan Sentani Kota, Kampung Sereh dan Kelurahan Hinekombe Kabupaten Jayapura, yang berlangsung sekitar 2 bulan, yaitu pada bulan Agustus - Oktober 2014. Alat yang digunakan dalam penelitian ini adalah kamera digital dan alat tulis menulis, dan bahan yang digunakan adalah Kuisioner. Metode yang digunakan dalam penelitian ini adalah metode deskriptif dengan teknik observasi dan wawancara dengan menggunakan Kuisioner.

Responden yang dipilih yaitu responden umum, dimana responden umum adalah masyarakat yang memanfaatkan areal pegunungan Cycloop sebagai lahan pertanian. Jumlah responden diambil secara acak yaitu sebanyak 26 responden yang meliputi wilayah Kelurahan Sentani Kota 10 responden, Kampung Sereh 10 responden dan Kelurahan Hinekombe 6 responden. Variabel penelitian yang diamati meliputi 1) kegiatan tindak agronomi terdiri dari pengolahan tanah, pola tanam, jarak tanam, pemupukan, pemeliharaan dan pengendalian hama penyaki tanaman; 2) kepemilikan luas lahan; 3) jenis-jenis komoditi; 4) pola unsur-unsur iklim dan 5) tindak agronomi berbasis konservasi. Data yang diperoleh dari hasil penelitian akan dianalisis secara tabulasi dan disajikan dalam bentuk tabel.

\section{Hasil dan Pembahasan}

\subsection{Kegiatan Tindak Agronomi}

Kegiatan tindak agronomi yang dilakukan oleh petani di sekitar area pegunungan Cycloop antara lain 1) pengolahan tanah; 2) pola tanam; 3) jarak tanam; 4) pemupukkan; 5) pengendalian hama dan penyakit tanaman Pengolahan tanah dilakukan dengan cara tanah digemburkan tanpa membersihkan serasah kemudian dibuat bedengan dan gundukan untuk menanam ubi jalar (Ipomea batatas) dan ubi kayu (Manihot utilisima). Berdasarkan hasil wawancara di lokasi penelitian terdapat $84,6 \%$ responden yang menggunakan pola tanam polikultur yaitu dengan menanam lebih dari satu jenis komoditi, hal ini dilakukan petani agar dapat memperoleh hasil panen yang beragam dan banyak, sehingga dapat menunjang kehidupan ekonomi masyaraka khususnya yang bermata pencaharian sebagai petani. Penggunaan jarak tanam yang dilakukan oleh masyarakat di areal pegunungan Cycloop masih sangat tradisional yaitu dengan menggunakan ukuran langkah kaki dan jarak tanam menggunakan tebakan (Felling). Pengaturan jarak tanam untuk setiap jenis komoditi telah diberikan oleh instansi terkait namun masyarakat tidak dapat memahami dan mengaplikasikan hal tersebut dengan baik dikarenakan tidak ada penyuluhan bahkan tindakan pendampingan secara langsung dilapangan untuk mempraktekkan cara pengaturan jarak tanam untuk setiap jenis komoditi.

Sebagian besar petani yang berkebun di areal pegunungan Cycloop tidak melakukan tindakan pemupukan namun ada beberapa petani yang melakukan pemupukan pada tanaman dengan menggunakan pupuk buatan dan pupuk alami. Alasan sebagian besar petani tidak melakukan tindak pemupukan karena harganya relatif mahal serta kurangnya pemahaman tentang penggunaan pupuk bagi tanaman disamping itu ada beberapa petani yang beranggapan bahwa dengan menggunakan pupuk pada tanaman dapat mengganggu kesehatan apabila tanaman tersebut dikonsumsi khususnya penggunaan pupuk kimia. Petani di sekitar pegunungan Cycloop belum memahami cara pemeliharaan tanaman seperti pengendalian hama dan penyakit tanaman yang baik seperti yang dianjurkan oleh instansi terkait, namun secara tradisional petani telah melakukan perawatan dan pengendalian hama penyakit tanaman dengan cara membaka rumput di sekitar kebun, hal ini dilakukan untuk mengusir hama seperti semut hitam dan belalang.

\subsection{Kepemilikkan Luas Lahan}

Distrik Sentani terdiri dari 2 kelurahan dan 1 kampung yaitu Kelurahan Sentani Kota, Kampung Sereh dan Kelurahan Hinekombe, namun untuk sementara Kampung Sereh masih merupakan bagian dari Kelurahan Sentani Kota karena belum resmi menjadi Kelurahan. Masyarakat yang bermata pencaharian sebagai petani sebagian besar masih memanfaatkan lahan diareal pegunungan Cycloop untuk bertani. Luas lahan yang digunakan masyarakat dalam pembuatan kebun bervariasi yaitu antara $600 \mathrm{~m}^{2}-1$ ha dengan luasan lahan rata-rata $2131 \mathrm{~m}^{2}$, meliputi Kelurahan Sentani Kota,Kampung Sereh hingga Kelurahan Hinekombe.

\subsection{Jenis - Jenis Komodit}

Berdasarkan data yang diperoleh dari responden di lapangan terdapat 19 jenis komoditi yang ditanam oleh masyarakat. Dari 19 jenis komoditi terbagi menjadi 2 bagian yaitu jenis komoditi tanaman pangan dan tanaman hortikultura. Jenis-jenis komoditi disajikan pada Tabel 1.

Data pada Tabel 1. memperlihatkan bahwa jenis komoditi yang dominan ditanam yaitu Ubi kayu (Manihot utilisima) dengan presentase tertinggi yaitu 69,23\%, Ubi jalar (Ipomoea batatas) 61,53 \%, dan Jagung (Zea mays) 57,69\% sedangkan untuk jenis komoditi yang paling sedikit ditanam yaitu Gambas dan Gedi dengan presentase terendah yaitu $3,84 \%$. Hal ini menunjukkan bahwa komoditi tanaman pangan lebih dominan jika dibandingkan dengan tanaman hortikultura, karena tanaman pangan dapat memberikan hasil panen yang banyak dalam waktu sekali panen disamping itu juga dapat dikonsumsi sebagai pengganti bahan pangan pokok serta memiliki nilai jual yang tinggi dan hasilnya dapat dimanfaatkan untuk memenuhi kebutuhan hidup sehari-hari, lain halnya dengan komoditi hortikultura yang lebih sedikit ditanam karena nilai jualnya yang dianggap rendah sehingga hal itu menjadi alasan utama mengapa masyarakat kurang menanam tanaman hortikultura. 
Tabel 1. Jenis komoditi yang ditanam oleh petani.

\begin{tabular}{|c|c|c|}
\hline No & Jenis Komoditi & Presentase $(\%)$ \\
\hline \multicolumn{3}{|c|}{ Tanaman Pangan } \\
\hline 1. & Ubi kayu (Manihot utilisima) & 69,23 \\
\hline 2. & Ubi jalar (Ipomoea batatas) & 61,53 \\
\hline 3. & Jagung (Zea mays) & 57,69 \\
\hline 4. & Kacang tanah (Arachis hipogaea L.) & 23,07 \\
\hline \multicolumn{3}{|c|}{ Tanaman Hortikultura } \\
\hline 5. & Nanas (Ananas comosus Merr.) & 7,69 \\
\hline 6. & Kacang panjang (Vigna sinensis) & 15,38 \\
\hline 7. & Papaya (Carica papaya L. ) & 26,92 \\
\hline 8. & Kacang buncis (Phaseolus vulgaris) & 19,23 \\
\hline 9. & Pisang (Musa sp.) & 26,92 \\
\hline 10. & Rica (Capsicum annum L.) & 11,53 \\
\hline 11. & Tomat (Lycopersicum esculentum) & 7,69 \\
\hline 12. & Gambas (Luffa acutangula L. Roxb. ) & 3,84 \\
\hline 13. & Sereh (Cybopogean nardus) & 15,38 \\
\hline 14. & Gedi (Abelmoschus manihot L.) & 3,84 \\
\hline 15. & Labu siem (Shecium edule) & 15,38 \\
\hline 16. & Labu cina (Benincasa hispida) & 3,84 \\
\hline 17. & Buah pandan merah (Pandanus conoideus) & 7,69 \\
\hline 18. & Jeruk manis (Citrus sp.), & 7,69 \\
\hline 19. & Alpokat (Persea americana) & 7,69 \\
\hline
\end{tabular}

\subsection{Pola Unsur - unsur Iklim}

Data unsur-unsur iklim yang digunakan dalam penelitian ini adalah curah hujan (presipitasi), suhu udara, dan kelembaban udara dengan panjang data pengamatan lima tahun. Penggunaan unsur-unsur iklim dalam penelitian ini adalah untuk mengamati pola dari masing-masing unsur iklim yang akan dihubungkan dengan tindak agronomi dan tindak konservasi yang dilakukan pada areal pegunungan Cycloop.

Curah hujan tertinggi terjadi pada bulan Maret dengan rata-rata 337,2 mm, kemudian terjadi penurunan curah hujan pada bulan April sampai dengan bulan Oktober. Pada bulan November rata-rata curah hujan mulai mengalami peningkatan hingga bulan Desember dengan rata-rata 198,8 mm. Rata-rata suhu udara bulanan di Kabupaten Jayapura, tertinggi terjadi pada bulan Desember dengan nilai $27,55^{\circ} \mathrm{C}$ dan suhu udara terendah terjadi pada bulan Juli dengan nilai $26,65^{\circ} \mathrm{C}$, hal ini terjadi karena radiasi matahari rendah dan curah hujan tinggi. Rata-rata kelembaban udara bulanan tertinggi di Kabupaten Jayapura terjadi pada bulan Juni dengan nilai rata-rata $84,88 \%$, hal ini terjadi karena radiasi matahari rendah kemudian suhu udara dan curah hujan tinggi. Kelembaban udara terendah terjadi pada bulan Oktober dengan nilai rata-rata $82,1 \%$, hal ini disebabkan karena radiasi matahari tinggi tetapi curah hujan dan suhu udara rendah.

\subsection{Tindak Agronomi Berbasis Konservasi}

Menurut Koestiono (2008) cit. Darmadi (2013) sistem usahatani konservasi yaitu mengkombinasikan teknik-teknik konservasi baik vegetasi maupun mekanik ke dalam sistem pertanian.

Konservasi tanah secara mekanik adalah semua perlakuan fisik mekanis dan pembuatan bangunan yang ditujukan untuk mengurangi aliran permukaan guna menekan erosi dan meningkatkan kemampuan tanah mendukung usahatani secara berkelanjutan.

Pada prinsipnya konservasi mekanik dalam pengendalian erosi harus selalu diikuti oleh cara vegetatif, yaitu penggunaan tumbuhan/tanaman dan sisa-sisa tanaman/tumbuhan serta penerapan pola tanam yang dapat menutup permukaan tanah sepanjang tahun. Perladangan berpindah oleh masyarakat migran Papua dan non Papua telah merusak kawasan hutan primer sebagai sumber penyaring dan penyimpan air. Proses perusakan lahan yang dilakukan secara terus menerus telah menimbulkan kondisi kritis pada beberapa kawasan (Purnomo, 2010) Dalam upaya mengatasi kondisi lahan yang kritis serta untuk meningkatkan produktivitas lahan, masyarakat harus memiliki pengetahuan dan menerapkan teknik konservasi tanah dan air meskipun sifatnya masih sederhana. Pengetahuan lokal yang harus dipraktekkan dalam upaya konservasi tanah, air dan tanaman antara lain: pengaturan pola tanam pada bidang olah, peningkatan kesuburan tanah dan ketersediaan air.

Berdasarkan hasil analisis pola curah hujan di wilayah Kabupaten Jayapura dapat dikelompokkan menjadi dua kategori yaitu basah (curah hujan >200 $\mathrm{mm} /$ bulan) dan sedang (curah hujan 100-200 mm/bulan) (DEPTAN, 2006).

Tabel 2. Pengaturan pola tanam di areal pegunungan Cycloop.

\begin{tabular}{ccc}
\hline Kriteria & Periode & Komoditi \\
\hline $\begin{array}{c}\text { Basah }(>200 \\
\text { mm/bulan })\end{array}$ & November - & Jagung + Pisang \\
$\begin{array}{c}\text { Sedang (100-200 } \\
\text { mm/bulan) }\end{array}$ & Apret & $\begin{array}{c}\text { Sayuran + Ubi jalar }+ \\
\text { Kacang panjang + Kacang } \\
\text { tanah + Ubi kayu }\end{array}$ \\
\hline
\end{tabular}

Tabel 2. memperlihatkan pengaturan pola tanam yang disesuaikan dengan kondisi curah hujan di Kabupaten Jayapura khususnya di areal pegunungan
Cycloop. Periode basah berlangsung dari bulan November sampai dengan Maret, pada bulan ini komoditi yang dianjurkan untuk ditanam adalah jagung dan pisang. Untuk kriteria kedua atau sedang yaitu berlangsung dari bulan April sampai dengan Oktober, pada periode ini jenis komoditi yang bisa ditanam adalah kacang panjang, kacang tanah, ubi kayu dan sayuran.

Kondisi curah hujan tinggi penyebab banjir, erosi, dan tanah longsor. Dengan demikian perlu dilakukan penanaman tanaman penutup tanah, dengan teknik konservasi tersebut selain menambah bahan organik tanah, dapat menghambat benturan curah hujan secara langung. Hal tersebut dapat menghambat erosi tanah pada kebun campuaran. Jenis legume merupakan jenis tanaman penutup tanah yang dianjurkan karena mengahsilkan bahan organik yang baik dan untuk keseimbangan hara tanah (Dariah et al., 2007; Fattet et al., 2011 cit. Erfandi, 2013).

\section{Simpulan}

Tindakan konservasi belum di terapkan dengan baik oleh petani yang melakukan aktivitas disekitar areal pegunungan Cycloop. Penggunaan tindak agronomi seperti jarak tanam, pola tanam, pengolahan tanah, pemupukan, pengendalian hama dan penyakit tanaman belum diterapkan secara baik oleh petani di sekitar areal pegunungan Cycloop. Sehingga perlu dilakukan pendampingan mengenai tindak agronomi yang tepat dengan mengutamakan prinsip-prinsip konservasi tanah, air, dan tanaman.

\section{Pustaka}

Ap. Fedrik, A. Roland, \& Daniel. 2010. Jurnal: Faktor-faktor Penyebab Kerusakan Hutan Dan Strategi Pengendaliannya (Studi Kasus Pada Cagar Alam Pegunungan Cycloops) Kabupaten Jayapura Provinsi Papua.

Darmadi D. E. 2013. Pengaruh Tingkat Penerapan Usahatani Konservasi Terhadap Produksi Dan Pendapatan Usahatani Sayuran Di Kecamatan Bumiaji Kota Batu. Tesis. Program Pascasarjana Universitas Brawijaya. Malang

Departemen Pertanian. 2006. Lampiran Peraturan Menteri Pertanian No. 47/Permentan/OT.140/10/2006, Tanggal 9 Oktober 2006. Pedoman umum Budidaya Pertanian Pada Lahan Pegunungan. Kementerian Pertanian Republik Indonesia. Jakarta.

Erfandi D. 2013. Teknik Konservasi Tanah Lahan Kering Untuk Mengatasi Degradasi Lahan Pada Desa Mojorejo, Lamongan. Jurnal Bumi Lestari, Vol 13 No. 1, hlm. 91-97

Purnomo, H. 2010. Konservasi Sumberdaya Lahan Dan Strategi Manajemen Wilayah Dikawasan Cagar Alam Pegunungan Cycloops (CAPC) Jayapura, Provinsi Papua.

Widianto, Sri Rahayu Utami dan Kurniatun H. 2003. Peran agroforestri pada skala plot. World Agroforestry Centre (ICRAF). Bogor. 